\title{
Analysis of the Histopathology, TNF- $\alpha$ of Microglia Cells Expression, NRG-I/erbB Oligodendrocyte, and Ki67/Apoptosis of Dentate Gyrus Rattus novergicus Brain After Acute Traumatic Brain Injury
}

\author{
Wibi Riawan $^{1^{*}}$, Putri Fitri Alfiantya ${ }^{2}$, Oktavia Rahayu Adianingsih ${ }^{3}$, Zulkarnaen $^{3}$, \\ Alif Fariz Jazmi ${ }^{2}$, and Sitti Ayu Hemas N. ${ }^{2}$ \\ ${ }^{1}$ Biochemistry and Biomolecular Laboratory, Faculty of Medicine Universitas Brawijaya, Malang, Indonesia \\ ${ }^{2}$ Undergraduate Program of Medicine, Faculty of Medicine, Universitas Brawijaya, Malang, Indonesia \\ ${ }^{3}$ Undergraduate Program of Pharmacy, Faculty of Medicine, Universitas Brawijaya, Malang, Indonesia
}

\begin{abstract}
Head trauma or traumatic brain injury (TBI) gives most serious impact on the central nervous system. Several experimental models have been established to mimic different pathogenesis characteristics of TBI. The purpose of this study was to determine whether there is evidence of hystopathological lesions in the brain tissue after Marmorou TBI models. This study uses Rattus norvegicus Sprague Dawley strain. Macroscopic and microscopic observations on the brain tissue were done. Macroscopic lesions were observed in the brain. Microscopic observation was performed with Haematoxylin-Eosin (HE) staining and immunohistochemistry on the distribution of microglia cells and pyramidal cells in the cortex. Meanwhile, the distribution of NRG-I/ErbB, proliferation, and apoptosis were observed in the hippocampus. The results of macroscopic observation showed that there were wounds caused by falling loads and vasodilatation. On microscopic observation, the TBI group showed an increase in neutrophils distribution and distribution of activated microglia to produce TNF- $\alpha$, and decrease in the number of cortical pyramidal cells significantly. The distribution of NRG-I tended to decrease after exposure of TBI and had no effect on its receptor, erbB. Exposure of $\mathrm{TBI}$ appears to lower the activity of neuronal cells proliferation in dentate gyrus (DG) area and significantly increase the number of apoptotic cells. Marmarou model is a physiological model of TBI that spontaneously occurs following a trauma to the head, for example trauma due to an accident. This data can be used as a preliminary data of inflammation and tissue regeneration of disrupted adult brain. Therefore, this research could be used as the basis in the studies of therapeutic agents in the process of neurogenesis of brain cells.
\end{abstract}

Keywords: traumatic brain injury, ERG-I/ErbB, dentate gyrus, Ki67, TNF- $\alpha$, microglia.

\section{INTRODUCTION}

Most Traumatic Brain Injuries (TBI) are causing a serious damage in the central neural system (Jorge, et al., 2005). Brain Trauma Foundation (2007) states that the main cause of TBI are dominated by the accidents of motor vehicles, sport injuries, and accidental fall. In Indonesia, particulary in DKI Jakarta, as many as $53.4 \%$ of casualties are recorded to have the serious injuries, especially in the head (Woro, et al., 2009). The head injury could induce cell damage, because the macrophages are doing phagocytosis to the tissue debris, resulting in inflammation (Murray and Thomas, 2011). The activated macrophage expresses interleukin-1 (IL-1), tumor necrosis factor- $\alpha$
(TNF- $\alpha$ ), IL-8, and IL-6 (Agarwal, 1995). TNF$\alpha$ induces the generation of reactive oxygen species (ROS). The increase of ROS would trigger the vascular endothelial cells to secrete e-selectine. IL-8 is the neutrophil chemotatic factor which induce neutrophil migration to the vascular endothelial cells. Neutrophil binds to e-selectine and secretes the metalloproteinase matrix (MMP) and collagenase, primarily MMP-8 (Holston, 1997). IL-1 plays an important role in inducing endothelial cells to secrete the vascular cell adhesion molecule (VCAM). VCAM is the adhesion molecule towards the monosit (Kuby, 2000).

\footnotetext{
*Corresponding author e-mail: wibiriawan@live.com
} 
The central neural system consists of neuron and glial. Neuron send the information to all parts of the body in the form of electrical signals through the axon and release the neurotransmitter in the synapses. Glia are composed of various cells which have the function to maintain and protect the neuron. Astrocytes and oligodendrocytes are the two main cells composing glia. Oligodendrocytes produce myelin, a membrane which is rich of lipid, to wrap axon. The function of myelin is to reduce the signal capacitance passing the membrane, and to increase the rate of electrical conduction in the axon. Oligodendrocytes are extending the length of myelin by some bumps, consructing the segments of myelin. Myelin membrane has a lot of lipid content and cholesterol as the main elements. Rats having defect in cholesterol synthesis showed retardation of myelinization (Darbas, 2004; Sherma and Bropy, 2005).

The management of post traumatic head is complicated, which includes the cognitive, emotional, and social rehabilitation (Block, et al., 2013). The decrease of cognitive, emotional, and social ability could be correlated with the continuous inflammation and the trauma of penumbra in the post TBI condition. Tobinick, et al. (2012) revealed that this process is likely caused by the activation of microglia and the significant increase of TNF$\alpha$. The abnormal behaviour caused by head injury could come as the result of axon damage. This process could cause the damage of myelin and/or the loss of olygodendrocyte, resulting in the inhibition of signal transduction, reduced the axon integrity, apoptosis of olygodendrocyte, and increased olygodendrocyte progenitor cells. The damage of axon caused by trauma suppress the synthesis of neuregulin-1 (NRG-1) protein. The role of NRG-1 is very important in the formation of myelin by oligodendrocytes (Calaora, et al., 2001). NRG-1 regulates some aspects of the olygodendrocyte development, including the life sustainability and migration of olygodendrocyte progenitor cells, and also its role in the myelinization process to control the thickness of myelin sheath related to the size of axon. The modulation of NRG-1 in the TBI would reduce the functional abnormality caused by myelin damage. The compensation mechanism in the prevention of myelin loss and death of olygodendrocytes could be developed as the new therapy targets for TBI (Flygt, et al., 2013).

The aim of this research is to determine whether there is evidence of hystopathological lesions in the brain tissue after TBI. The research also quantify the neutrophils, TNF- $\alpha$ expression of microglial cells, and the number of pyramidal cells in the cortex. The observation of the hypocampus damage was done by the observation of the number of apoptotic cells and the loss of DG's renewal ability. Olygodendrocytes were determined by the observation of NGR-1/erB distribution in the hippocampus area.

\section{MATERIALS AND METHODS}

This study was done in vivo by randomized post-test only controlled group design. As many as 32 rats (Rattus novergicus Sprague Dawley strain) with the body weight of $350( \pm 20)$ grams were divided into two groups. The first group (16 rats) were not given any treatment as control group and the other 16 rats were given the treatment of TBI as the study done by Marmarou (2009). The rats were anesthetized and then the head fur were shaved and wiped with $70 \%$ ethanol. Then the scalp were dissected. A 45-gram-iron cylinder (4 mm in diameter) was dropped by the angle of $90^{\circ}$ from the height $100 \mathrm{~cm}$ once. After the treatment, the scalp was sutured again. Two hours after the treatment, the rats were necropted and the brain tissue were isolated (Marmarou, et al., 2009).

The brain tissue were fixed by $4 \%$ paraformaldehyde for 24 hours. The steps were dehydration, clearing, impregnation, and blocking. The tissue was cut with the thickness of $6 \mu \mathrm{m}$ and stained by the Hematoxylin-Eosin. Immunohistochemistry staining was done to see microglial cells distribution (anti lba-1, abcam cat\#ab15690), pyramidal cells (EMX-1 scbt biotech cat\#sc-28220), hypocampus cells proliferation in DG area (Ki67 scbt biotech cat\#sc-15402), NRG-1 distribution (anti NRG1 cusabio cat\#CSB-PA016077GA01HU), ErbB (anti erbB scbt biotech cat\#sc-285), and apoptosis (Roche cat\#11684817910).

The slides of HE and immunohistochemistry staining were observed by Olympus CX21 microscope and examined. The observation was done by calculating the cells observed in 20 field of views with the 
magnification of $1000 x$, approximately 1500 cells.

The data were then analyzed by T-test. The ratio of the number of KI67+ and apoptotic cells were used to obtain proliferation index. The expression of NRG-1/erbB were obtained in the form of picture as the representation of each groups from the parameter observed.

The picture were obtained by using Panasonic Lumix-G3 camera in the Olympus CX21 microscope with the magnification of 400x.

\section{RESULTS AND DISCUSSION}

\section{Macroscopic Observation}

The macroscopy damage existed in the brain after TBI (Fig. 1).

\section{Neutrophils Distribution in the Cortex and Brain Tissue Hippocampus Exposed by TBI}

To study the inflammation process, this research observed the distribution of neutrophils in the brain tissue. The sectional preparations of brain were stained with HE and showing the neutrophil distribution in the cortex and hippocampus (Fig. 2).

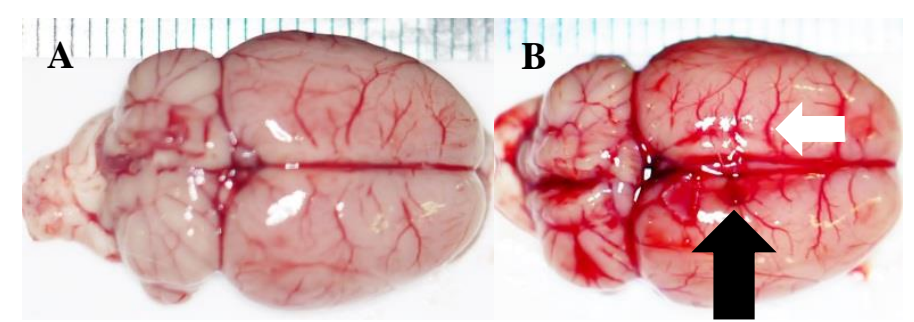

Figure I. Macroscopic figure of brain tissue exposed by TBI (B) compared to control group (A) showed damage which is noted with arrow.

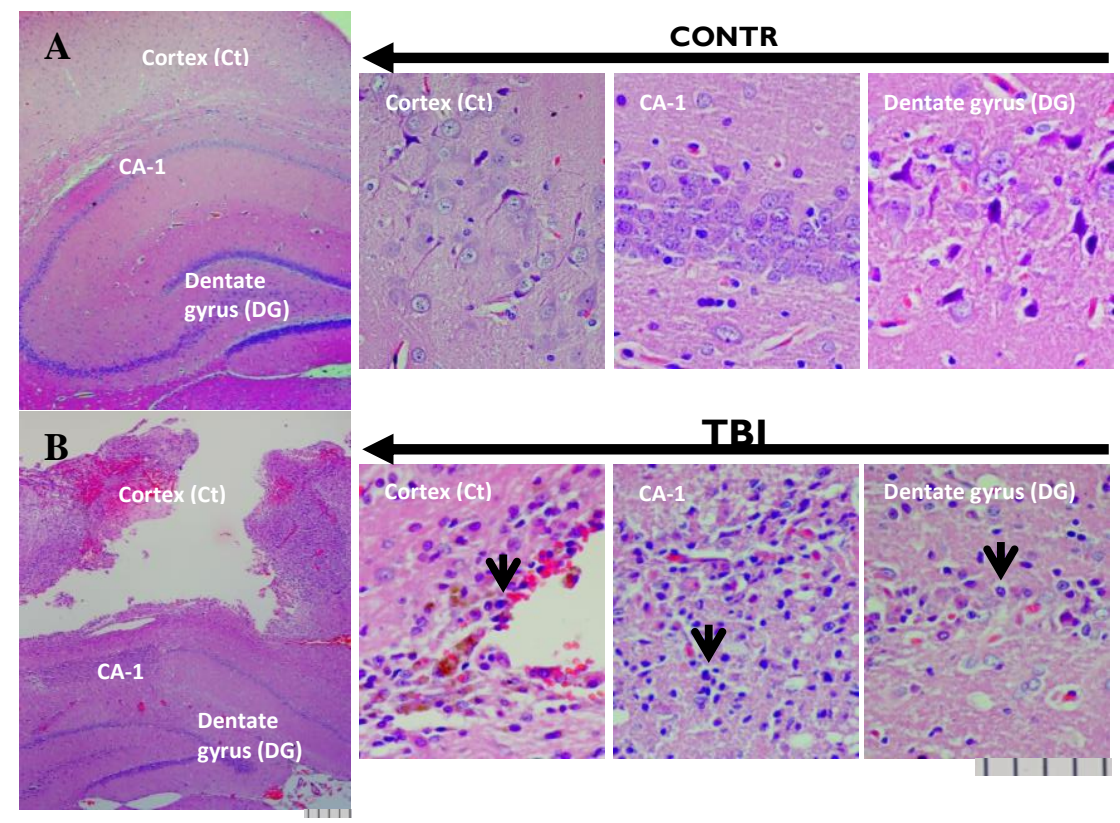

Figure 2. Horizontal section of brain tissue stained by HE showed the distribution of neutrophils in cortex (ct), CA-I and dentate gyrus (DG) after TBI exposure (B) which are noted by arrow. Figure $A$ as the control without TBI exposure, showed the absence of neutrophils in ct, CA-I, and/or DG. The observation was done under Olympus CX21 microscope, 1000x magnification. 
The Increase of Activated Mycroglia in the Cortex of Brain Organ treted by TBI

After the TBI treatment, the reactive microglia deposited in the injury location (Dihné, et al., 2001) where they play a role in the phagocytosis of damaged cells and cell debris. The acute lession of the activated mycroglia peak happen 2-3 days after the stimulus and happen continuously as long as the stimulus exist (Banati, 2003). In the immunohistochemistry staining, two types of staining were used to observe the increase of mycroglial cells (red) and the expression of TNF- $\alpha$ (brown). The results showed the increase of mycroglial cells producing TNF- $\alpha$ in the cortex of brain tissue after the treatment of TBI exposure (Fig. 3).

\section{The Decrease of the Pyramidal Cells in TBI-treated Brain Cortex}

This study observed the distribution of pyramidal cells as the main component of cortex in brain tissue. Immunohistochemistry staining was conducted to see the amount of microglial cells using EMX-1antibody (Chan, et al., 2001). The result showed a significant decrease $(p<0.05)$ in the amount of pyramidal cells in the cortex of brain tissue after TBI exposure compared to control group (Fig. 4).

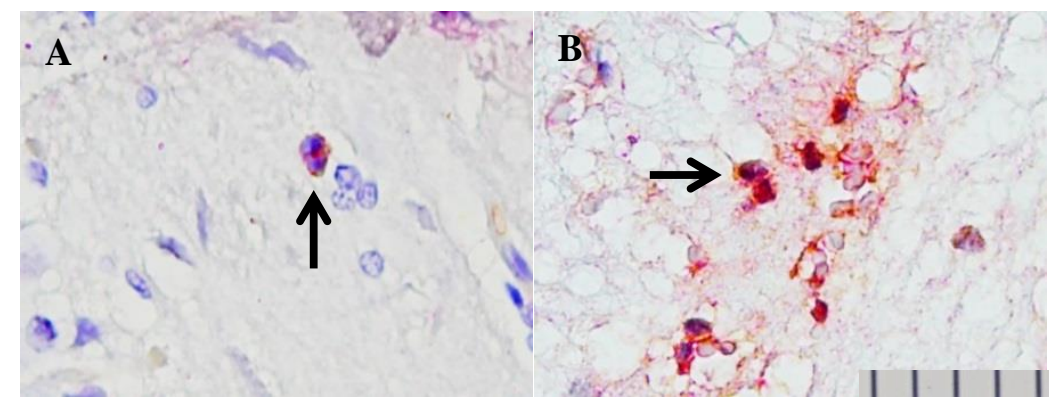

Figure 3. The figures represents the immmunohistochemistry staining of TNF-alpha visualized by DAB (brown) using anti TNF-alpha in microglial cell visualized by fast-red (red) using anti Iba-I. The figures were taken with $400 x$ magnification. Figure $A$ is control group. B is TBI group. The arrow shows the the distribution of TNF-alpha in cell cytoplasm.

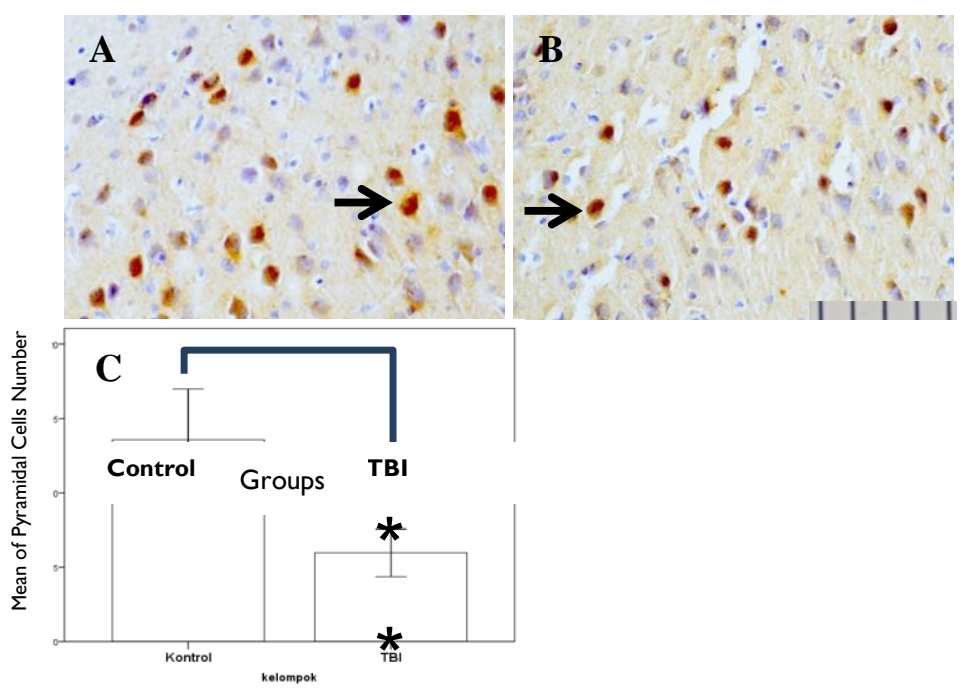

Figure 4. The effects of TBI in the number of pyramidal cells in the cortex of brain tissue. The figure shows the immunohistochemistry staining of pyramidal cells visualized by DAB (brown) using anti EMXI with 400x magnification for control group (A) and TBI gropup (B). The number of pyramidal cells decrease significantly in TBI gropus $(p \leq 0.05)(C)$. 


\section{OligodendrocyteNRG-I/erbB Expression}

The observation of the effect of TBI in the expression of NRG-1 and its receptor, erbB was conducted in hippocampus, CA-1, using immunohistochemistry technique, with specific antibody to observe the expression of each protein.

The effects of TBI in the distribution of NRG-1and erbB on oligodendrocyte cells can be seen at Fig. 5.
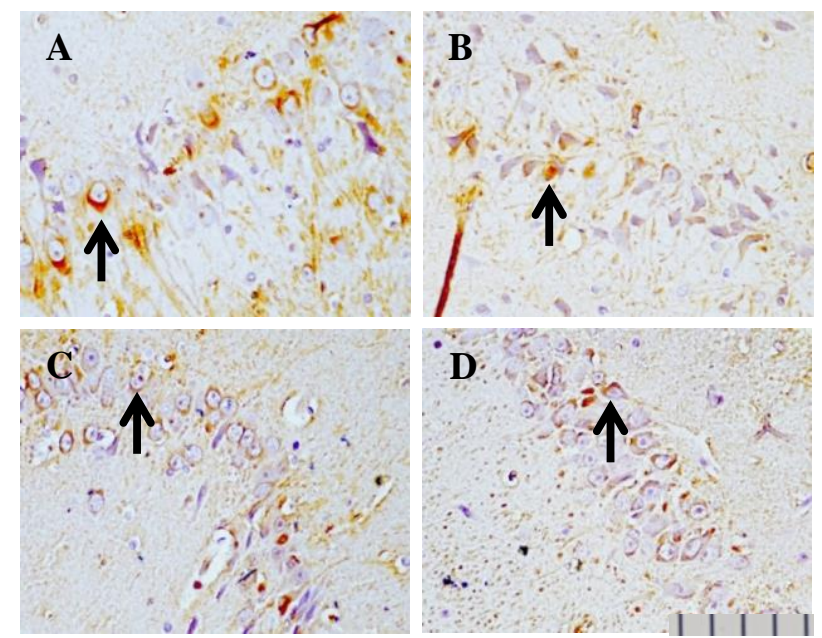

Figure 5. The effects of TBI in the distribution of NRG-Iand erbB on oligodendrocyte cells. Immunohystochemistry was done by DAB staining (brown color). Compared to the control group (A), NRG-I expression decrease after TBI (B), while the erbB expression in the control group (C) is slightly the same as the TBI group (D).

\section{The Use of $\mathrm{Ki}-67$ in Brain Tissue, Especially in Dentate Gyrus Hippocampus}

The use of Ki-67, nuclear protein is stated as the mitotic process of the cell. Ki-67 can be detected by immunohistochemistry. Ki67 is the endogen marker which is safe for viable cell. Although the function of Ki-67 hasn't been known yet, but it is a reliable marker to reveal the mitotic process. Besides, recent study reported that $\mathrm{Ki}-67$ presents in mitotic process of mammals, including human (Scholzen and Gerdes, 2000). The study focus on the use of Ki-67 in brain tissue, especially in dentate gyrus hippocampus, because of the possibility of the neuronal cell proliferation consequence in cognitive and behavior
(Boonstra, et al., 2001). The interesting topic in TBI research is the patophysiology process after traumatic condition or tissue recovery and neuronal cell regeneration. TBI exposure showed a significant decrease (Fig. 6C) of Ki67 expression in cell nucleus in DG area (Fig. 6B) compared to control group (Fig. 6A). Positive expression of Ki-67 noted with brown color in nuclear cell (Fig. 6A-B; arrow).

Apoptotic data are showed to observe the decrease of proliferation caused by the increase of apoptotic cells in DG area. The result showed significant increase of apoptotic cell in DG area after TBI exposure (Fig. F) compared to control group (Fig. 6E). The Equipment for TBI can be seen at Fig. 7. 

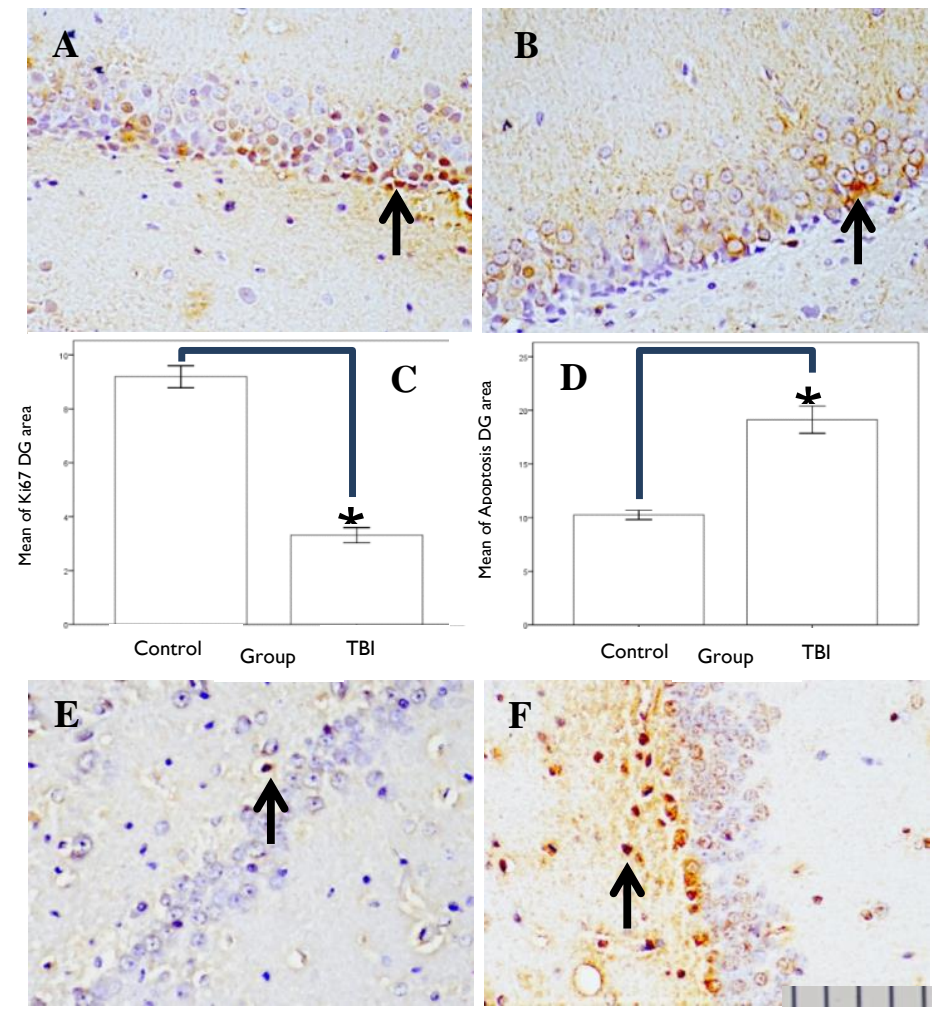

Figure 6. The effects of TBI on the distribution of Ki67 by DAB immunohistochemistry staining and the number of apoptotic DG area neuron cells. The figures show distribution of the Ki67 in the control group (A), and TBI group (B). The number of Ki67 distribution decrease significantly after TBI treatment (C). Meanwhile, the number of apoptotic DG area neuron cells increase signifiantly (D). The apoptotic DG area neuron cells in control group $(E)$ and TBI group $(F)$ are shown in the figures.

Patophysiology cascade activated by traumatic brain injury (TBI) and caused penumbra injury with certain limit will be discussed. In the other part of this discussion, the certain aspects of acute patophysiology cascade started after TBI exposure will be

focused, such as the decrease of NRG-1 which is related with myelination. Pathophysiology process in the chronic phase of brain after traumatic condition or tissue repairment and regeneration will not be discused here.

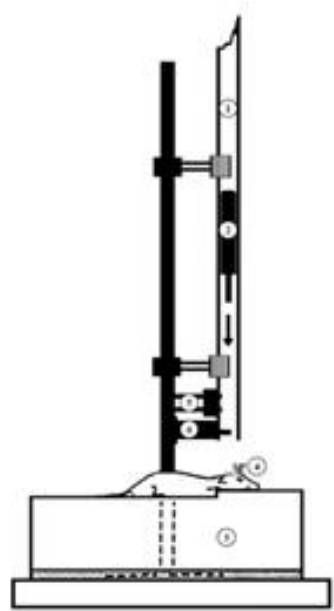

Figure 7. The Equipment for TBI (Marmarou, 2009). 
TBI causes a big social-economic load all over the world. Nowadays, the most general model is fluidic flow model, whereas the injury is caused by short fluidic pressure continued directly in the dural surface intact, so that brain injury is formed. This research is developed based on TBI technique which is conducted by Marmarou (2009). Based on our preliminary study, TBI exposed by 430 grams load dropped at such height resulted a high mortality level (>50\%). Hence, we used 1 meter height and 45 grams load.

Marmarou model, although is rarely used, could represent physiology model of spontaneous brain injury. Observation to afterTBI-exposed-brain photo-macrograph showed the reddish injury in middle part of brain, udema, and vascular dilatation. The occurence of ishaemic cerebral followed by inflammation reaction in injured part may continue in days or weeks. Histology observation by photomicrograph of after-TBI-brain tissue preparations showed the extreme increase of neutrophils after TBI exposure. The condition after brain injury regulates the increase of proinflammation cytokines directly and indirectly (Maas, et al., 2000; Dokka, 2001).

Cytokine plays role in vasodilatation that cause the increase of blood flow, increase of neutrophils and monocytes keeping the homeostatic condition by the increase of blood coagulation, angiogenesis and cell proliferation induction, induction of acute phase response (APR). However, the inflammation response is not only mediated by immunocompetent cells which is differentiated from bone marrow and erythorcytes. Synchronized with leukocytes infiltration, immuncompetent recident cell activation in brain tissue like microglia and astrhocytes then happen.

Microglia covers $20 \%$ of the total amount of brain cells and become active after brain injury. The active microglial cell developes amoeboid morphology. Like leukocytes, active microglia produces some pro-inflammation cytokines. Cell debris caused by tissue injury caused microglia activation. Microglia activation process started by cell and tissue inflammation is caused by lesion and ischaemia. Active microglial will produce proinflammation factors such as TNF- $\alpha$. If this factor is not well regulated, it may cause an excessive destruction. Active microglia will release glial-derived neutrophic factor and activate nuclear factor kappa B (NF-kB) (Tobinick, et al., 2012). NF- $\mathrm{kB}$ is one of trancription factor which turns TNF- $\alpha$ gene expression on. The study showed that there is an increase of TNF- $\alpha$ expression in TBIexposed microglial cells (Fig. 3).

One of the direct response of proinflammation cytokine increase is the induction of APR. The aim of this study is to observe the distribution of pyramidal cells. Cerebral cortex in mammalia consists of a number of neuron and glial cell. This kind of cell is arranged in different cytology and functional structure. Majority of cortical neuronal cells is pyramidal cells that could be found in all layers except the first layer (Chan, et al., 2001). The loss of pyramidal cells is important because of its dominant characteristic. We hypothesize that the significant loss of pyramidal cell is the effect of APR. The increase of TNF- $\alpha$ production by microglial cell increase the expression of many pro-inflammation cytokines such as IL-1 $\beta$, IL-6, and IL-8.

Based on the results of the study, we predict that the significant decrease of pyramidal cells amount is related with the increase of pyramidal cells apoptosis. This apoptotic pathway interfere CD95 protein or Fas reseptor (TNF reseptor family) with Fas ligand called TRAIL (TNF-Receptor Apoptosis Inducing Ligand) which lead to apoptosis extrinsic pathway. In the beginning, ischaemic injury in TBI is caused by energy failure, the increase of intracellular calcium, and the release of amino acid with exitotoxicity. This process will activate ischaemic failure mediators, including free radicals production, peroxynitrite, calpain, phspholipases, and PARP. Simultaneous with the beginning of apoptotic pathway, the inflammation gives the contribution to the development of tissue failure. Secondary phase of cell death may include the long term changes in macromolecules and the other important metabolites. The whole process may become a potential target to therapeutic intervention.

TBI in human is caused by a severe hit in the head. Some experimental models have been built to imitate pathogenetic characteristic different from TBI. There are two main kinds of TBI, that are closed and permeable TBI. Based on the use of permeable TBI model, this study characterized the destruction probability other than in the cortex area. The important thing is 
the role of oligodendrocytes in signaling process. An important feature in vertebral neuron system is the formation of myelin, together with signal tranduction effectivity and the protection role of axonal neuron system. Oligodendrocyte is myelinating cell from central neuron system. Oligodendrocyte forms many extentions. Each of the extention forms myelin after connect the axone. Because of the sythesis and the conservation of myelin, oligodendrocyte is very active in metabolism process. Therefore, oligodendrocyte become sensitive to lipid peroxidation and DNA damage caused by oxidative stress. Therefore, we know that oligodendrocytes death and myelin degradation is the common feature in acute and chronic central neuron system diseases, such as trauma, ischaemia, bone marrow injury, Alzheimer disease, and schizophrenia (Bradl and Lassmann, 2009). Finally, demyelinisation will produce axonal degeneration and the decrease of neuron function. The result of this study showed that there is a tendency of the decrease of NRG-1 oligodendrocyte expression after TBI exposure. While for NRG-1 receptor, erB, no difference was observed. We observed that the acute process did not affect myelinization regulation. Further study of NRG-1/erbB regulation in TBI needs to be conducted.

Functional role of adult neuron in neurogenesis regulation is still debatable. Many studies have found the result being in contrary with the new role of cell in hippocampus. It depends on the memorial function (Saxe, et al., 2006; Imayoshi, et al., 2009). Some studies revealed that neuronal proliferation regulation in adult mammalian brain tissue happen spontaneously in lateral ventricle and subgranular layer of hippocampus (Fig. 8).

This concept become interesting when we relate it to the injury condition, showing how important neurogenesis in adult brain tissue is when injury occurs. After TBI exposure, the brain tissue injury did not only happen in cortex area, but also in hippocampus area, CA-1, and DG (Fig. 2B). We used a specific marker for proliferation process. The results of Ki67 staining (6A-B) showed the decrease of DG regeneration ability in TBI brain model (Fig. 6B). The decreased regeneration (proliferation) including apoptosis are showed in Fig. 7B. DG area is part of the hippocampus which has neurogenesis ability in adult brain (Kee, et al., 2002). This data could be used as the preliminary data of injured adult brain tissue regeneration in the DG. Therefore, this study provides the basis for more advanced studies of therapeutic agent in adult brain neurogenesis process and also the developement of experimental knowledge in adult hippocampal neurogenesis function. Finally, it could help us understand the relevance of research in human healthy brain and abnormal brain (Nottebohm, 2002; Lindsey and Tropepe, 2006).

\section{ACKNOWLEDGEMENT}

We acknowledge Student Research Grant (HPM) Program, Universitas Gadjah Mada who has funded this research in 2011.

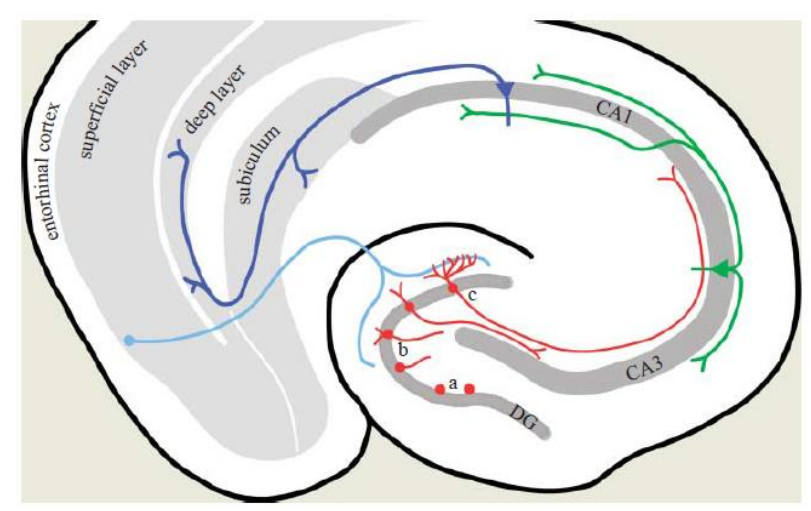

Figure 8. The figure of neurogenesis in hippocampus whereas the progenitor cells are divided in subgranular layer (A). New born of neuron migrates in short distance to DG layer (B) and will reach mature condition (C) (Amrein and Lipp, 2009). 


\section{REFERENCES}

Chairungsrilerd, N., Furukawa, K., Ohta, T., Nozoe, S. and Ohizumi, Y., 1996, Pharmacological Properties of Alphamangosteen, A Novel Histamine $\mathrm{HI}$ Receptor Antagonist, Eur. J. Pharmacol., 3 I 4(3), 35I-356.

Fujioka, S., Sclabas, G.M., Schmidt, C., Frederick, W.A., Dong, Q.G., Abbruzzese, J.L., et al., 2003, Inhibition of Constitutive NF-kappaB Activity by Ikappa Balpha $M$ Suppresses Tumorigenesis, Oncogene, 22, 13651370.

Gavrieli, Y., Sherman, Y. and Ben-Sasson, S.A., 1992, Identification of Programmed Cell Death in situ via Specific Labeling of Nuclear DNA Fragmentation, J. Cell Biol., I I 9(3), 493-50I.

Gewies, A., 2003, Introduction to Apoptosis, Apo Review, I-26

Ho, C.K., Huang, Y.L. and Chen, C.C., 2002, Garcinone E, A Xanthone Derivative, Has Potent Cytotoxic Effect Against Hepatocellular Carcinoma Cell Lines, Planta Med., 68(I I), 975-979.

Hung, S.H., Shen, K.H., Wu, C.H., Liu, C.L. and Shih, Y.W., 2009, Alpha-Mangosteen Suppresses PC-3 Human Prostate Carcinoma Cell Metastasis by Inhibiting Matrix Metalloproteinase- 2/9 And Urokinase-Plasminogen Expression Through The JNK Signaling Pathway, J. Agr. Food Chem., 57(4), I29I-I 298.

Jorge R.E, Starkstein S.E, Arndt S., Moser D., Crespo-Facorro B. and Robinson R.G., 2005, Alcohol Misuse and Mood Disorders Following Traumatic Brain Injury, Archives of General Psychiatry, 62(7), 742-749.

Levrero, M., Laurenzi, V.De., Constanzo, A., Sabatini, S., Gong, J., Wang, J.Y.J., et al., 2000, The p53/p63/p73 Family of Transcription Factors: Overlapping and Distinct Functions, J. Cell. Sci., I I3(I0), 166I-1670.

Matsumoto, K., Akao, Y., Ohguchi, K., Ito, T., Tanaka, T., linuma, M., et al., 2005, Xanthones Induce Cell-cycle Arrest and Apoptosis in Human Colon Cancer DLD-I Cells, Bioorg. Med. Chem., I3, 6064-6069.
Moongkarndi, P., Kosem, N., Kaslungka, S., Luanratana, O., Pongpan, N. and Neungton, N., 2004, Antiproliferation, Antioxidation And Induction of Apoptosis by Garcinia Mangostana (Mangosteen) on SKBR3 Human Breast Cancer Cell Line, J. Ethnopharmacol,, 90(I), 16I-166.

Nabandith, V., Suzui, M., Morioka, T., Kaneshiro, T., Kinjo, T., Matsumoto, K., et al., 2004, Inhibitory Effects of Crude Alpha-Mangosteen, A Xanthone Derivative, on Two Different Categories of Colon Preneoplastic Lesions Induced by I, 2-Dimethylhydrazine in The Rat, Asian Pac. J. Cancer Prev., 5(4), 433-438.

Nakagawa, Y., linuma, M., Naoe, T., Nozawa, Y. and Akao, Y., 2007, Characterized Mechanism of Alpha-MangosteenInduced Cell Death: CaspaseIndependent Apoptosis With Release of Endonuclease-G from Mitochondria and Increased Mir-143 Expression in Human Colon Cancer DLD-I Cells, Bioorg. Med. Chem., I5(I6), 5620-5628.

Renvoizé, C., Biola, A.M., Pallardy, M. and Bréard, J., 1998, Apoptosis: Identification of Dying Cells, Cell Biol. Toxicol., I4(2), III-I 20.

Ribble, D., Goldstein, N.B., Norris, D.A. and Shellman, Y.G., 2005, A Simple Technique for Quantifying Apoptosis in 96-well Plates, BMC Biotechnol, 5, 12.

Ricci, M.S. and Zong, W., 2006, Chemotherapeutic Approaches for Targetting Cell Death Pathways, The Oncologist, I I (4), 342-357.

Thompson, H.J., Strange, R. and Schedin, P.J., 1992, Apoptosis in the Genesis and Prevention of Cancer, Cancer Epidemiol Biomarkers Prev., I (7), 597-602.

Turini, M.E., and Dubois, R.N., 2002, Cyclooxygenase-2: A Therapeutic Target, Ann. Rev. Med., 53, 35-57

Weecharangsan, W., Opanasopit, P., Sukma, M., Ngawhirunpat, T., Sotanaphun, U. and Siripong, P., 2006, Antioxidative and Neuroprotective Activities of Extracts from The Fruit Hull of Mangosteen (Garcinia mangostana Linn.), Med. Princ. Pract., I5(4), 28I-287.

Winawer, S.J., 2007, Colon Cancer Screening, J. Clinical Gastro., 2 I (6), I03 I-1048. 